\title{
A Life Shaken: My Encounter with Parkinson's Disease
}

\author{
by Joel Havemann \\ The Johns Hopkins University Press, \\ $200 \mathrm{pp}, \$ 24.95,2002$
}

\section{Reviewed by STEPHen B. DunNetT \\ School of Biosciences, Cardiff University Cardiff, Wales, UK}

A Life Shaken is an account of one remarkable man's experience living with Parkinson's disease. Joel Havemann is still working as a senior editor for the Los Angeles Times, 14 years after receiving a diagnosis of the disease. Everyone has their own way of coping with problems; Havemann's is to turn his journalistic skill to dissecting and analyzing his disease. The result is a challenging mixture of dispassionate appraisal of the facts and lucid portrayal of his personal experiences adapting to living with the disorder. The account works on three very different levels.

First is the sensitive account of a literary scholar struggling to live with Parkinson's disease. Havemann is a survivor, and his ability to adapt is an inspiration of equal value to patients, caregivers, clinicians and research scientists alike. He brings a wry humor to his account, exemplified by some of the dafter advice he has received, from how to maximize his sightseeing of cathedral roofs as a tourist to how to "realign his body energy down to theta" through acupuncture. This is combined, however, with a clear and practical take on anti-parkinsonian drugs and their side effects, sleep, diet, exercise, and organization of his daily life. His successful coping is attributable in part to his optimism and willpower. However, he also confronts the conundrum that his ability to maintain independence is dependent on the help and support of others. Most notable are his neurologist Stephen Reich, who is quoted extensively; his employers at the Los Angeles Times, who have been willing to promote the career of a skilled journalist while he has all the while been developing progressively more disabling symptoms; and the support and space provided by his wife and children.

Second, Havemann reveals his journalistic skills in a masterful summary of our present knowledge about Parkinson's dis- ease, alongside present and future therapeutic options. The information is provided as a cogent and accurate account of the biology and medicine of this disease for the lay reader, and can also serve as a useful refresher for the non-specialist academic. Nevertheless, since the book is targeted at a general audience, it is perhaps surprising that the illustrations are all black-and-white technical drawings that appear to come straight out of standard biomedical textbooks and will almost certainly be incomprehensible to the nonspecialist. In this instance, the whole presentation would have benefited from the graphic artistry of a media colleague to complement the author's writing skills.

As well as gathering biomedical information on the disease itself, Havemann also recounts the political reality of health care delivery, primarily from an American perspective, but includes an interesting contrast with Europe acquired during a three-year post in Brussels. He encounters both advantages and disadvantages to socialized medicine, finding it great when the system works but preferring the American insurance model as more dependable for when it doesn't. Although it would be easy for me as a Brit to offer a supercilious response, I was struck by the muddying of public and private practice that the author met when he came to the United Kingdom for a consultation with one of our British medical heroes (you will have to read the book to identify the names!). Certainly the energy and effectiveness of patient support and pressure groups in the United States give added credence to the American approach, with the author perhaps not surprisingly favoring the campaigning style of the Parkinson's Action Network and Michael J. Fox Foundation over the more genteel pressure provided by the traditional Parkinson's societies.

Third, and perhaps of most interest for the Nature Medicine readership, is the critical perspective turned on us scientists and medics. In particular, the willingness of the clinicians who have interacted with the author over the last decade to allow their detailed clinical notes to be reproduced is striking, and these provide an intriguing parallel commentary to the author's personal account. My own interests were captured most strongly, however, when Havemann turns his focus to current and future surgical therapies, a topic on which he expresses a remarkable optimism about the progress of medical science. The rationale and different techniques for deepbrain lesions and stimulation surgery are cogently described, along with the personal experiences of several colleagues who have followed this route. Havemann considers that the potential risks associated with the irreversibility of lesions mean they have a limited future in the litigationprone culture of the United States, and he is much more upbeat about deep-brain stimulation as a better way forward.

As potential therapies, fetal tissue transplants, stem cells, neurotrophic factors and neurophilins are all considered. Although several of these alternatives are controversial in the present climate, the account is noteworthy not only for its balance, but also for the view that they should each be investigated and weighed on their scientific merits. Havemann has donned his journalistic hat here and interviewed many of the key players in the field; his accounts of their individual and personal perspectives will be of interest to anyone working in this area. Pressed with the personal urgency of finding effective cures now, Havemann finds little support for the activities of "zealots" who prejudge the issues and seek to limit research options on non-scientific, emotional or political grounds.

So, for whom is this book written? For newly diagnosed patients and their families, Havemann offers a mixture of determination, optimism and facts presented with the elegance and clarity we would expect from a professional journalist. For the clinician, Havemann is generous in his account of his own experiences and forthright in his plea for patients to be approached as participants in, rather than as objects of, their diagnosis and treatment. For the scientist, the book provides a sensitive insight into the hopes and fears of the thousands of patients, which brings focus and urgency to our research. But ultimately, A Life Shaken was written for the author himself, as his own way of coping with his developing disease using the tools and skills he knows best. The elegance and professionalism that he brings to this task provide not just a 'good read,' but through his synthesis of scientific, clinical and personal perspectives, an inspiration for all. 